\title{
Are we getting the message across? Trends among young men attending an inner city young people's clinic
}

\author{
C Armitage, B Curran, S Wright, K Lenehan, P Kell
}

Sex Transm Infect 2004;80:477-479. doi: 10.1136/sti.2004.011262

Background: A young people's clinic has been running at the Archway Sexual Health Clinic since 1997. This offers a weekly walk-in service to both young men and women under 20 years old.

Objectives: To review the audit data of over 7 years' experience from the dedicated young people's clinic at the Archway Sexual Health Clinic, the "Arch."

Methods: These data were collected by retrospective notes review of a consecutive series of all male attendees over a 7 year period from 1997 to the end of 2003 with collection of data in Microsoft Excel database.

Results: These figures show an overall increase in attendee numbers, but also a relative rise in the numbers of young men using the service. A high number of bacterial sexually transmitted infections were detected. In 2001 and 2003 respectively, $14.5 \%$ and $17.8 \%$ of the young men using the service were diagnosed with Chlamydia trachomatis. A user survey aimed to identify factors that may be encouraging the young men to access the service.

Conclusions: Responding to the views of young men using the service has played a part in service development. Initiatives at the "Arch" such as the condom policy and choice of gender of staff may be factors encouraging increasing attendances. Continuing to work with other agencies to develop ways to engage young men are recommended. Word of mouth recommendation cannot be underestimated in publicising the service.

Y oung people in the United Kingdom continue to carry the burden of high rates of sexually transmitted infection and this is acknowledged in the national sexual health strategy. ${ }^{1}$ The number of uncomplicated Chlamydia trachomatis infections rose by $16 \%$ in young men between 2001 and 2002. ${ }^{2}$ The rationale for young people's services in genitourinary medicine has been well documented. The structure of the service must meet the needs of the user group and be mindful of the difficulties perceived by the young people accessing the service. ${ }^{3}$ Nationally, the percentage of young men accessing young people's sexual health services is low, with estimates between $3-20 \%{ }^{4}$

The "Arch" at the Archway Sexual Health Clinic is a weekly clinic dedicated to the under 20 s and offers sexual health screening, contraception, and condoms along with advice without accessing the other services. The clinic is located in an economically deprived and ethnically diverse area of north London in the borough of Islington; 75\% of attendees are resident in the borough of Islington and its neighbours Camden and Haringey. ${ }^{5}$

\section{METHOD}

Each clinical episode is documented on a proforma used solely in the young people's clinic. For the past 3 years, the data from these proformas have been entered into a Microsoft Excel database by the health advisers at the end of the clinical session. This has ensured ongoing access to regularly updated data.

A user satisfaction survey was distributed during the clinic session over a 6 week period in April and May 2003. The survey was anonymous and was returned to central collection boxes in different areas in the clinic. Questions covered access to the service and how users felt it could improve. The last part of the questionnaire was a tear-off section requesting details for those who agreed to be contacted to participate in single sex focus groups.

\section{RESULTS}

\section{Attendances}

Between 2002 and 2003, there has been a 260\% increase in the numbers of young men using the service. In the first few years of opening, young men made up $10 \%$ of overall attendees but this increased to $26 \%$ in 2003. In 2003 in addition to the 523 who attended for STI screening, 97 attended for condoms only (see fig 1).

\section{Age distribution}

The mean age is 18.5 , with more than $70 \%$ in the $18-20$ year age group.

\section{Ethnicity}

Fifty four per cent of young men describe themselves as being from an ethnic minority group; $25 \%$ described themselves as black Caribbean in origin and $11 \%$ of men described themselves as of black African origin. The ethnic mix of the young men attending the young people's service does not mirror the ethnicity of the population living locally. Data from local population figures indicate that $10 \%$ identify themselves as Afro-Caribbean and another 10\% state they are of black British origin.

\section{Diagnosis of STIs in attendees}

In 2003, 93 (17.8\%) male attendees had Chlamydia trachomatis compared to $21(14.5 \%)$ male attendees in $2001 ; 21 \quad(4.0 \%)$ male attendees in 2003 had gonorrhoea compared to 16 (11\%) in 2001.

In $2003,46 \%$ of men using the service were asymptomatic at the time of first visit, compared with $32 \%$, in 2001 . Clinic data for diagnoses among female attendees during the same period revealed that $10.6 \%$ had $C$ trachomatis and 3.2\% had gonorrhoea. Sixty eight per cent of young men using the service in 2003 accepted HIV testing compared with 38\% in 2001 . 


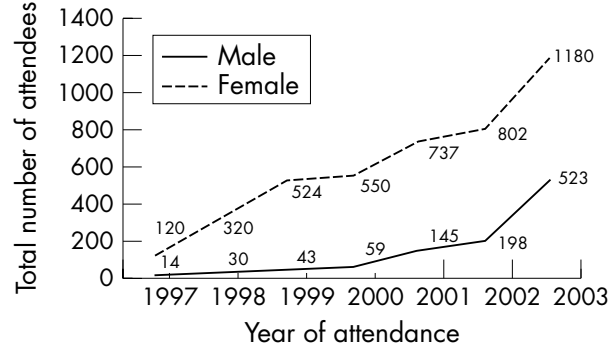

Figure 1 Annual number of attendances at the "Arch" between 1997 and 2003.

\section{The user satisfaction survey results}

Twenty five young men completed the survey-116 forms were completed in total. The majority of respondents (83\%) thought that the service was confidential. The young people described this as encouraging them to attend.

Helpful staff and the walk-in facility were also cited as encouraging factors; $67 \%$ of the male respondents heard about the clinic from friends; $72 \%$ of the young men completing the questionnaire had already used the service before this attendance. Only one young man wished to join a focus group.

\section{DISCUSSION}

There have been several initiatives that may have been responsible for the increase in male attendees.

Liaison with other groups working with young people Links with other services are being developed with the aim to access more young men. Staff from the "Arch" have liaised with a counselling centre that targets young men. Liaison with primary care has led to the creation of a nurse led young people's service in the surgery of a local general practitioner. A youth worker has been providing support to those attending by giving the young men the opportunity to talk about alcohol, drug use, and lifestyle issues outside the clinical consultations.

"SASHES" (student access to sexual health/education about services) has been developed with the local sexual health education team with groups of pupils from schools visiting local sexual health services. Evaluation of this by the local sexual health education team (SHET) in 2002 showed that young people involved were more aware of local services.

\section{The condom policy at the "Arch"}

A policy for condom distribution was set up in the clinic in 2000 and may have contributed to the increased number of young men using the service for STI screening. This intervention came about to cope with the large numbers of young men attending the clinic at times outside the "Arch" session wanting to take advantage of the offer of free condoms. An evaluation of this intervention showed that the majority of young men attending were aged 13 and 14.7\% were not sexually active at the time of questioning; $88 \%$ of young men had heard about the service from a friend. ${ }^{6}$

\section{Choice of gender of staff}

The clinic staff has changed over the last 5 years and now includes male doctors, nurses, health advisers and psychologists, so young men attending will have the choice of gender of staff involved in their care. Having a gender mix among staff also helps to change the image of a female dominated service, which could deter some young men from attending.

\section{User involvement}

The user satisfaction survey distributed among the young people attending the clinic generated some feedback, but the numbers were small. The focus groups were promoted with posters in local schools, youth clubs, colleges, GP surgeries, and another local sexual health clinic. These posters generated a positive response but the groups were poorly attended.

\section{The appointment policy}

A survey carried out at a London sexual health clinic showed that boys in the 11-14 and 15-18 year age groups favoured the drop-in option rather than phoning in advance or walking in and booking an appointment for later. ${ }^{7}$ The clinic at the "Arch" is a walk-in clinic: doctors, specialist contraception nurse, and health advisers can all be accessed without a previous appointment. Follow up appointments can be made after the first clinical episode for review or results. This differs from the appointment system during the rest of the week when it is appointment only, made by telephoning 24 hours in advance or by nurse triage.

All attendees under 16 are seen by the health adviser before their clinical consultation to help complete the registration process and assess competency along Fraser guidelines, including one on one work with young men at an early stage in their attendance has been cited as good practice. ${ }^{8}$

\section{CONCLUSION}

There has been an increase in the number of young men attending the young people's service at the Archway Sexual Health Clinic. Feedback has been sought from the young people using the service by both questionnaires and open forum. The service continues to explore ways of encouraging young men to screen for sexually transmitted infections. A website with the option for interaction has been developed and may provide another point of access for young people: this can be located at www.archwayclinic.org.uk.

\section{ACKNOWLEDGMENTS}

The authors wish to thank the health advisory team for their role in data collection.

\section{CONTRIBUTIONS}

CA, BC, and PK drafted and revised the manuscript text; SW, BC, CA, and KL undertook data extraction, analysis, and interpretation from the clinic database.

\section{Authors' affiliations}

C Armitage, B Curran, S Wright, K Lenehan, P Kell, Archway Sexual Health Clinic, Clerkenwell Wing, Archway Campus, London N19 5NF, UK

Conflict of interest: None.

An oral presentation of the same title was given at the "Siam Care" 3rd international meeting on sexual and reproductive health, Chiang Mai, Thailand, February 2004 (by the co-author CA). The oral presentation covered data from December 2002 to May 2003. This paper covers data from 1998, 2001, and 2003 not previously published.

Correspondence to: Catherine Armitage, Archway Sexual Health Clinic, Clerkenwell Building, Archway Campus, The Whittington Hospital, London N19 5NF, UK; Catherine.armitage@Camdenpct.nhs.uk

Accepted for publication 29 July 2004

\section{REFERENCES}

1 Department of Health. The national strategy for sexual health and HIV. London: Stationary Office, 2001.

2 Health Protection Agency website. www.hpa.org.uk/infections. 
3 McMorrow S, Kell P. Teenage sexual health; are specific clinics the way forward? Int J STD AIDS 2002;1:4-6.

4 Springall L. Encouraging young men to access sexual health services. Let's hear it for the boys. Chapter 4. London: National Children's Forum, 1997.

5 Burns F, Curran B, Tobin R, et al. Inner city adolescent sexual health-cause for concern? Int J STD AIDS 2002;1:52-4.
6 Wright S, Tobin R, Kell P. A novel policy for condom provision for the under 16s. STI 2001;77:287-8.

7 Nwokolo N, McOwan A, Hennebry G, et al. Young people's views on provision of sexual health services. Sex Transm Infect 2002;78:342-5.

8 Teenage Pregnancy Unit. Best practice guidance for the provision of effective contraception and advice services for young people. London: 2000, www.info.doh.gov.uk/tpu/tpu.nsf. 